\title{
Exploration on Interaction Design Curriculum System and Talents Training Mode
}

\author{
Jian Zhang \\ Sichuan Fine Arts Institute \\ Chongqing, China 401331
}

\begin{abstract}
Introduce development background and present situation of interaction design education; discuss objective of talents training, curriculum provision, teaching method and teaching practice system of UI design in art major and put forward some ideas of talents training mode according to requirements of new design and talents training; explore UI curriculum system and talents training mode that are more suitable for the major of art design.
\end{abstract}

Keywords-interaction design; UI; art and design; curriculum; talents training

\section{DEVELOPMENT BACKGROUND AND PRESENT SITUATION OF INTERACTION DESIGN EDUCATION}

With the arrival of information society, contemporary design enters an unprecedented new stage. The typical characteristic is dematerialization of design objects, so it leads to changes of design requirements, design contents, design methods and design forms. The continuous connotation and extension of art design also put forward new requirements of talents training for design education.

UI is the medium of interaction between human and information. It is the functional carrier and typical characteristics of information products. There is no restriction for information products on craft and material. Excellent UI designer is one of its core competitiveness. At present, UI visual designers mainly come from graphic design and industrial design. In general, they lack systematic theoretical understanding for UI design, only relying on personal exploration and accumulation. However, unspecialized training mode has been unable to meet the requirements of industry for talent output. Especially when smart phone and mobile internet comprehensively surpass PC, many IT enterprises intensely compete for professional talent resources of UI art and design related to mobile platforms and products. Therefore, it is in urgent need of related majors in art academies to establish scientific discipline and curriculum system of UI art and design and cultivate professional and high quality talents of UI art and design.

At present, the biggest problem faced by talents training of UI design is the lack of professional and systematic teaching. There are few UI design majors with complete disciplinary system in our country. Only few specialized institutions open UI design courses. Related curriculum construction is also at

Science and Technology Research Project of Board of Education in Chongqing City, Research on Graphic Language of Internet Mobile Terminal Interface, project number: KJ1400801. the stage of development. The construction and improvement of UI design courses help to cultivate talents of UI design with more professional qualities, improve quality of digital products, strengthen competitiveness, and also broaden professional knowledge area and employment space for students in major of art design, as well as explore effective ways and methods to further establish and consummate UI design major.

\section{ANALYSIS ON PRESENT SitUATION OF UI DESIGN COURSES IN ART MAJOR}

UI design in art major is in the initial stage of development in domestic art and design education. There are few institutions to open courses related to it, lacking sufficient experience. The research on UI design teaching remains to be improved and deepened. The professional teaching at the present stage mainly has shortcomings such as unreasonable and imperfect curriculum system setting, inadequate training of innovation ability, vague teaching model and impossible to fully meet the requirements of industrial development. It also directly leads to critical shortage of design talents in urgent need with professional quality. From the perspective of construction status of UI design courses, it mainly has the following problems.

- Teaching Materials Is Not Professional and Systematic. As a new-rising subject, teaching materials of UI design haven't formed scientific and complete system, lacking systematic teaching materials from theoretical culture, vocational skills and training of comprehensive innovation abilities to guide students to carry out UI art and design step by step.

- Curriculum Has no Professional Pertinence. There are few complete teaching designs that aim at characteristics of art majors and conform to its knowledge background and learning style; lack systematic carding of relationships between overall framework of UI design and visual design, and disaggregate approach as well as guiding and systematic analysis of UI design platform and industry; the setting of professional basic courses lacks professional pertinence. All in all, it is necessary to combine with specialized characteristics and new trend of development, make appropriate adjustment on the basis of the original courses and carry out distinctive professional course design. 
- Systematic Course System. Because of no setting of direction for UI design major, single UI design course has relatively isolated curriculum provision, lacking cohesion and continuity between courses. If former courses do not solve software skills, it may distract the attentions paid to design skills and creativity because of technical reasons; without latter sufficient courses of practical creation, it is impossible to change knowledge into ability. Interdisciplinary UI design and extensive correlative field and application also decide that it is difficult for single course to guarantee the deepness of teaching and learning. Therefore, courses shall not be isolated and closed, but have close relationships with former and latter professional courses and jointly form complete UI design course system in art major.

- When emphasizing visual design ability, UI design courses in art major shall pay attention to preliminary planning and prototype design. The leading-in of interaction and the concept of user experience also remain to be strengthened.

- Course contents have no relationship with practicality and application, lack leading-in of industrial standard. It is difficult to turn teaching results into products.

\section{UI COURSES IN ART MAJOR AND ANALYSIS ON TRAINING OBJECTIVES OF DESIGN TALENTS}

The talents training of UI art and design needs to train technical skills, arts and humanities accomplishment, creative thinking as well as promote the accumulation of comprehensive knowledge and abilities such as psychology. Comprehensive abilities required by talents of UI art and design are mainly embodied in cognition of UI design industry, practical and employment abilities.

\section{A. Job Functions of UI Designers Roughly Contain Three Aspects}

- Visual design, including static and dynamic graphic design on interface of information products, visual design of information.

- Interaction design, mainly including information architecture, interactive prototypes and operation specification of products, etc.

- User experience design, including user research and user test, rationality and usability of interaction and aesthetic experience of graphic design.

\section{B. Vocational Abilities of UI Designers Generally Include}

Solid foundation of basic skills in fine arts and good visual expression; abilities to masterly use related design software such as Photoshop, Flash, Dreamweaver, Illustrator, After effects and 3dmax; preliminarily know about relations and logic between background and program development; deeply understand user experience, knowledge reserves of humanities such as sociology and psychology; rich imagination and creativity.

\section{Course Objectives and Talent Training Objective}

On the basis of professional orientation of related discipline background of art and design as well as specific circumstance of training program, according to characteristics of teaching subject, seek different curriculum plan and targeted teaching contents, enhance advantage and avoid disadvantage, teach students in accordance of their aptitude, emphasize exerting professional advantages in aspects such as visual aesthetic, artistic accomplishment and hands-on practice, pay attention to developing students' creative thinking and potentials in design planning, artistic expression and interaction design.

The course objective of UI design can be defined as: cultivate talents of UI design with innovative ideas and practical operational ability, through modular teaching of basic knowledge and skills and teaching of item practice of professional ability, make students master core theory of interfacial design, basic standard and specification, design process and method and skillfully use related software to finish several small types of UI designing scheme. The core mission of the course is to train UI visual design ability of students and make them have specialty literacy more suitable for industry needs.

\section{Design OF TALENTS TRAINING Mode OF UI ART AND DESIGN}

After determining talents training objective, it needs to design concrete means and methods to achieve the goal. The design of talents training mode of UI art and design can be divided into four levels: comprehensive qualities cultivation, professional skills training, optimization and improvement of curriculum system, improvement and innovation of teaching contents and methods. Through optimization and reorganization of teaching contents, train comprehensive quality and professional skill of students and improve their creativity and innovation ability.

\section{A. Comprehensive Quality Training}

1) Modeling ability: mainly including training of artistic performance ability. Combine with major courses such as drawing, quick sketch, color and three-dimensional contouring, carry out training with professional pertinence.

2) Aesthetic accomplishment: Train ability to analyze and judge aesthetics character of existing UI design works. Appreciate and compare different types of UI, widely absorb pattern of manifestation of excellent works in fields of art and design, accumulate visual experience.

3) Imagination and creativity: Imagination is the source of art design and innovation. In thematic design of icon, carry out specialized training of graphic creativity and association, brainstorming and visual storm in team design and stimulate imagination and creativity of students.

4) Communication and expressive ability: In the course of UI design, it often embodies communication power of expression. User study needs communication, which is also needed between different team members. Designers need to clearly express design thought and creativity to customers and 
team members. They can set project team splitting in courses and train communication power of expression of students in ways of group discussion, scheme elaboration and mutual evaluation of works.

5) The ability to observe and perceive: Train sensibility of students for characteristics and details of things and emotional awareness, which can guide sensible intuition and rational intuition for UI design. In design practice, guide students to imitate and experience, comprehend and master, emphasize comprehension and direct experience, instead of simply paying attention to knowledge and rational analysis.

6) Autonomous learning ability: UI designers face constant changes of design tools, design objects and pattern of manifestation and need to have the ability of continuous selfdirected learning. Let students start with imitational design and study independently by relying on a large number of learning resources on the internet.

\section{B. Professional Skills Training}

1) Ability to write documents: UI designers need to have good communication and comprehensive ability, write reports of product markets and user study, design guiding principles and standards to provide basis for implementation of followup visual design, program design and test. Teachers can let students write UI design documents in course teaching to improve students' ability of literal expression.

2) Technical skills: UI designers shall at least know about mainstream development technology of presentation layer and have enough understanding for mainstream design pattern, technical route and open-source framework. It needs to have compiling of simple script code and elementary teaching in the face of object-oriented programming type in courses. Even though they cannot edit code, they need to know what it can realize. UI designers who totally cannot understand technology will not be able to make reasonable design and achieve effective communication with developers.

3) Sketch drafting and prototype development: The main tasks of GUI designers are visual positioning and creation, so UI designers must have the ability of graphic design, which is the initial and the most basic ability of each UI designer. It can furthest measure the ability level of UI designers. In courses, both rough draft and prototype design require to draw complete and elaborate manuscript and present clear steps and design thought. Carry out analysis, appreciation and specialized training of design style and detail performance.

4) Ability to design plane figure, three-dimensional figure and dynamic graphics: It involves software application ability and needs to masterly use software to carry out design and production of UI visual elements, which is the necessary skill of UI visual designers.

5) Ergonomics theory and cognitive psychology: It is the field that needs UI designers to spend the rest of their lives in making efforts to explore after their career is on the right track. So to speak, the essence of design is "human". In order to make human centered interface, it naturally needs to know about human being as well as their behaviors. In the course, combine UI design with design psychology and guide students to pay attention to designs of user study and user experience.

\section{Optimization and Improvement of Curriculum System}

Establish teaching model that combines modular teaching of professional skills (professional basic knowledge and training of skills) with introduction of teaching of item practice (training of vocational ability and literacy) of industrial standard.

\section{1) Modular teaching of professional skills}

a) Specialty foundation: In basic courses of modeling and design, teach by consciously aiming at UI design, such as in teaching of introduction to sketch, pay more attention to training of space composition, light and shadow and texture. In the training of three components, add time element and train students' thinking ability of dynamic construction. Set Interactive Animation Design and Dynamic Graphic Design as antecedent professional courses of UI design.

b) Professional theory: Courses include connotation and classification of UI, characteristics of UI design, development history of GUI; relationship between cognition and design, human factors engineering in UI design; psychological and physiological basis in the back of UI design criteria, deeply understanding of user experience; analysis and implementation in UI integrated design, such as user and task analysis, market and target analysis, information architecture, UI prototype design; metaphor, visual principle and visual process in UI visual design, art language of UI design and design of UI visual elements, etc.

c) Software skills: Skill practice module mainly lets students grasp the use of graphic design software related to UI design through typical case teaching and runs through course teaching and practical teaching links. The overall thinking focuses on design philosophy and creative way of thinking and takes the teaching of software techniques as subsidiary role. The proficiency of design software and promotion of operative skills of students mainly depend on autonomous learning after class, instead of relying on classroom teaching with limited time.

d) UI topic design module: Topic design module includes icon design, Web UI design, UI design of software, UI design of game, UI design of mobile devices.

e) UI systematic design: Use the model of student team to carry out practice of small UI systematic design scheme.

2) Introduce teaching of item practice of industrial standard: When courses enter relatively in-depth phase, after students grasp complete related knowledge and have certain design capability, introduce practice project in line with the industry. Thus can make students further know about characteristics and limitations of UI design in product development process, such as specific user groups, clear and limited design period, control of quality, communication and 
coordination with customers, and cultivate their specialty literacy in complete design flow and team creation.

\section{Improvement and Innovation of Teaching Contents and Methods}

1) Teaching students in accordance of their aptitude: Aiming at specialty orientation of different discipline background, establish multilevel teaching scheme of UI design with emphasis and individuality. For example, in teaching of digital media specialty, pay attention to application of UI design in game field and mobile APP; in teaching of industrial design specialty, attach importance to application of UI design in fields of vehicle-mounted digital products and products of internet of things; students in art education major are inclined to the application of UI design in fields of cultural diffusion and education software. Besides, set assignments for students in different design majors, make use of personal interest of students to give play to advantages of each student.

2) Group coordination: UI design is the gem of wisdom of teams, needs teamwork to design and carry out repeated test and iteration. A whole product is not the combination of several single UI. A UI design task with full scale can be set and jointly finished by some students. In propulsion of task, set group leader to plan and control progress of task and general statement, use brainstorming to carry out creativity of UI visual and interaction design; after the creation begins, group members are responsible for design of a certain part respectively according to their characteristics. Grouping task can stimulate students' creative passion, train team spirit and ability of mutual cooperation and guarantee quality and efficiency of design works.

3) Pay close attention to industry trends: On teaching contents, pay attention to trend and dynamic condition of industrial development. Nonmaterial design objects have rich forms and contents, change and develop all the time. On the basis of sector demand and dynamic condition, continuously improve and adapt to major curriculum system and contents and methods of course teaching, refer to classic case in the industry to analyze and imitate and then carry out independent creative design.

4) Design of practice project: Practice project includes course practice and industry practice. On one hand, refer to relatively mature cases to simulate; on the other hand, combine with related commercial items and let students truly integrate in design practice of the industry. As continuity of course practice, the creation of student team can depend on student studio or college students' creative planned project. Industry practice can rely on design research institution of the department or professor's studio, or strategic cooperative enterprises to carry out industry practice training, and depend on industry-university-research cooperation mechanism of the department to discuss new model of industry practice teaching.

\section{CONCLUSION}

Improve training program of UI design education, strengthen scientific and systematic research on UI design education, combine with market needs and industrial standard, start with objectives of teaching and talents training, base on the existing course teaching and practical creation, improve, extend and optimize teaching contents and explore systems, contents and methods of UI design course teaching that conform to the background of major of art design. Carry out research on reform and practice with distinguished features according to UI design theory and practical teaching related to major of art design and cultivate talents of design with high quality and strong comprehensive abilities.

\section{REFERENCES}

[1] Ding Kai, Li Hui. Research on Interface Design Originality of Modular Curriculum System in Interactive Media Art, Journal of Nanjing Art Institute, 2012(06)191-195.

[2] Liu Yi. First Exploration on Interaction Design Teaching under Studio System, Decoration, 2013(03)143-144. 